\title{
PRESIDENTIAL ADDRESS OPPORTUNITIES AND CHALLENGES AHEAD FOR HILL COUNTRY FARMING
}

\author{
P. GARDEN \\ Avenel Station, Millers Flat, Central Otago \\ pat.marcelle@farmside.co.nz
}

One of the pleasures of flying across our country on a good day is to enjoy the sight of the landscape crawling by beneath. And what a landscape we have! It is a remarkably wrinkled, green and hilly terrain interspersed with patches of arable country. Hill country sheep and beef farming systems cover much of the farmed area of New Zealand - probably around 8 million out of the 11.5 million hectares of grazing/arable land. That figure recognises that a hill country enterprise is usually an integrated system - predominantly breeding, perhaps with some deer, will often have forestry and increasingly, moving more to fattening at least a proportion of the surplus stock. Climate varies hugely across the hill country land use area with droughts and dry periods requiring adaptive systems to manage the risk of feed shortage. Products able to be generated from this land type include: meat, carbon, fibre, wood, energy and ecological services such as biodiversity and landscape values.

In looking at the opportunities and challenges ahead, I am going to take a five to 10 year view rather than focus on the impacts likely to be experienced over the next year or so. If we confined ourselves to the short term, all the discussion would be about currency, cost of fertiliser, interest rates and predicted rainfall - none of which we could greatly influence! My focus is more on global trends and the nature of the land.

My address to you is based on my observations and experience from a lifetime on the land not from data and the results of trials. I'm a little nervous about that, especially as I am usually the first one to insist "Show me the science!" when someone claims to have uncovered a truth. If you do feel moved to throw something to emphasise your opposition to any views stated, please ensure that it has a readily realisable monetary value and I will make sure it goes directly into the NZ Grassland Account.

I need to warn you before going any further that I am a supreme optimist about NZ pastoral farming. I believe the future is as exciting as it was when I began farming in the 1960s and my passion for it burns just as brightly after all those years. That enthusiasm, that faith in the future is based around our competitive advantage over other producers of food and natural services elsewhere in the world. The competitive advantages are not restricted to the good grass growing climate or the clean green image so often promoted as our differentiation but include the support systems - transport, processing, marketing as well as what I refer to as the knowledge flow business within our industry. That includes the research sector developing our understanding of processes, the commercialisation of that knowledge through products and services for the pastoral industry, and the innovative ways farmers apply both concepts and products within their enterprises. We should never underestimate the value of that knowledge infrastructure - that flow of ideas and insights.

I think we do it as well as anywhere else in the world and this Grassland Conference is a valuable part of that dynamic. It's not to say for a moment that we couldn't do better - our crossbred wool structures and the machinations of all the entities that have come and gone is an appalling indictment of sheep farmers; the meat industry has not yet delivered on its potential, and we could do much better yet in the uptake of R\&D on the farm.

There is clearly work to do at home...but I would like to turn now to some of the big global issues that are going to provide the backdrop for our pastoral industry over the next few years.

\section{Global Issues}

For me, the single biggest issue by a country mile is the combination of green house gases, climate change and water. Our future as pastoral farmers and producers of food will be inextricably entwined with how this will unfold over the next decade or so, not just on the global stage but directly on farm. I know many of my fellow farmers are sceptical and view global temperature change - if indeed it is happening - as just another event in an ancient series of warming and cooling cycles and that man's contribution to global warming is insignificant when put against the magnitude of the earth's natural events. I am not in that camp.

Certainly the issue is so complex and has so many inter-related components that it is almost impossible for a layman to get a handle on, but there is a huge body of excellent science supporting the case for urgent action to control emissions across the board. I am looking forward to the session tomorrow morning which will 
explore the issues at a more detailed level. I would like to come back to how the Greenhouse Gas (GHG) emissions question might affect us on farm later, and for the moment consider global warming - whether man-induced or not.

One of the most disturbing features for the global community over the next few years is the threat to food supply. Now I know there have always been doomsday scenarios about the imminent shortfall in available food with widespread starvation certain to follow but there does seem to be a consistent thread: increasing severity of droughts coupled with equally devastating floods across important food producing areas are having a real effect on food security.

Last year a number of $\mathrm{NZ}$ farmers and scientists attended the International Rangeland and Grassland Congress in Hohhot, Inner Mongolia, China. There were some interesting insights. Inner Mongolia is a huge grassland area, carrying large numbers of cattle and sheep once managed on a nomadic grazing system. Through the $80 \mathrm{~s}$ and $90 \mathrm{~s}$, as part of the policy of self sufficiency in food, grassland regions were encouraged to increase production and livestock numbers increased dramatically. But the overgrazing that resulted combined with worsening droughts has resulted in desertification on a huge scale. At the end of last century it all came to a head. The huge flood of the Yangtze in 1998 killed 4000 people. It was followed by a series of violent dust storms affecting Beijing in 2000 and 2001. Grassland policy became a national priority and widespread grazing restrictions with their accompanying social upheaval are now a permanent feature of the huge grassland areas of China.

Water availability is the next big factor. Overuse of ancient slow recharge aquifers is going to have a dramatic impact on food production, particularly in the great North Plain of China which has two thirds of the crop land but only a fifth of the water. Many of the shallow irrigation wells have been abandoned as the water table has dropped and ever deeper ones drilled combine all that with the widespread contamination of waterways and China has massive issues to confront. And in case you need reminding, we are talking about $20 \%$ of the world's population and $7 \%$ of the available water.

Looming water shortages from ancient aquifers is not limited to China. The huge Ogallala aquifer under the High Plains in the American Mid West is also under pressure. The water dates back to the last ice age and has been used to irrigate what has become one of the most productive cropping areas in the States supplying 20\% of total US agricultural output. Because the Ogallala has a very slow recharge, its current rate of depletion will need to be urgently addressed or its productive life could be limited to a mere 25 years. Less water intensive crops and a reduction in current productivity will be an inevitable part of those changes.

If one adds a world population growth of another billion people every $12-13$ years, it seems to me almost regardless of the emphasis one might put on the scale and impact of these sorts of global environmental events, the pressure on food supply over the next decade is going to be immense. Food prices will reflect that pressure and the implications for an efficient, sustainable livestock industry based on our hill country extensive systems are part of the reason why I am so excited about the future.

Let me put it another way. Let's say you were going to invest long-term in commodities. You have two options - energy and resources as represented by say BHP Billiton or food as represented by the meat and dairy industries of NZ - where would you invest? (Of course, as a conservative southern sheep farmer my advice would be to have a bob each way, as both look mighty attractive!)

\section{New Zealand Opportunities}

Capitalising on those opportunities back home on our hill country farm is not going to be straightforward. Let's come back down to earth after our global jaunt into the future and look at some of the on-farm issues. I'm going to start with carbon and the Emission Trading Scheme (ETS). When I wrote this paper there was still no clarity about the shape of things to come but regardless of the final outcome, farming will have to front up. Whatever the scepticism within the farming community, the concept has such a buy in from global consumers and governments and such momentum that purely from a pragmatic perspective; we farmers need to start planning for how we are to best deal with it. Regardless of whether the New Zealand contribution of $0.21 \%$ of global GHG emissions is regarded as inconsequential or not, the overseas consumer is not going to accept our product unless it has paid its carbon dues. I do think though that the hill country sheep and beef operation is being asked to bear an unequal share of the cost. If we look at the change in methane emissions from sheep and beef between 1990 and 2010, sheep have dropped $21 \%$ and beef has risen $3 \%$. Dairy on the other hand has increased $97 \%$ over the same period. The increase in methane for the period of 20 years taken across the whole livestock sector is $15.7 \%$. Seems to me there would be a strong argument for delaying the entry of the sheep and beef sector into the Emission Trading scheme for another couple of years beyond the dairy sector.

I don't believe there is any real mileage in seeking credits by building up soil carbon. Our developed pasture land already has good levels of soil carbon and once we set off down that track any loss of carbon from the soil will become a liability. That strikes me as a 
very risky game. For me, the most obvious balancing of the carbon liability from livestock emissions will be with carbon credits from growing trees, particularly as trees are such a natural fit within hill country livestock enterprises. If the carbon liability at harvest could be delayed to reflect the actual decay time scale of the timber after its useful life ended, we would have a real proposition that we could work with. Indeed, I am confident that my enterprise could handle the future liability around livestock methane emissions, provided forest harvest carbon liability was connected to actual wood decay and that my competitors also had to cover the cost of livestock emissions. Unfortunately, everything is mired in Kyoto protocols but that is the sort of trade off that NZ must negotiate if it is to accept more ambitious GHG reductions in Copenhagen.

\section{Farm Debt Levels and Risk Appetite}

I'd like to turn now to a structural issue - debt levels and risk appetite. Since 2005 farming debt levels have risen by $40-50 \%$. That is a huge lift and is probably the single biggest issue affecting farmer's confidence. Banks have tightened up their criteria and many farmers feel locked into a heavily mortgaged future with returns insufficient to pay off debt. This is exacerbated by violently fluctuating returns driven by the recent global economic malaise and a stubbornly bullish NZ currency. Over the past few years farmers have increased their wealth but made no money.

One of the contributing factors for greater debt levels has been expansion into more land and the accompanying development. I'm going to be brutal here, but I have to say that when the purchase price of land escalates from a once steady 3-5 times gross turnover to $10-12$ times gross turnover in a game with fluctuating returns and fluctuating seasonal conditions, the risk appetite has moved into dangerous territory. It has seemed that land purchase was more about real estate investment rather than an investment in the productive values of that land and it has kept young people with insufficient equity out of land ownership and attracted corporate investors who may have the resources to sit it out. It has also resulted in greater intensification and higher input costs to maximise the return from the land. It has been a real dilemma for enterprises needing to expand - do you pay the market rate and gamble on returns rising or do you sit on the sidelines and watch the opportunity slide by?

My assessment for the future is that successful hill country enterprises will need to build in more buffers against risk. Lower stocking rates to give some flexibility in times of climate-induced stress, financial buffers to protect against volatility in returns and an ongoing focus on maintaining a low cost grass-based system with good performance targets. The question is, will the value of land allow this sort of precautionary approach to be priced into the equation - I'm not so sure, if only because of the sorts of drivers affecting food supply I spoke about earlier. I am convinced that a capital gains tax to dilute the attractiveness of asset appreciation and speculation inherent in current farmland investment is long overdue.

\section{Ecological Values and Services}

The 8 million hectares of hill country farm land includes a huge asset to the nation in terms of natural values, both in terms of biodiversity and valued landscapes. The vast majority of farmers recognise those values and are keen to integrate them into their enterprises. One of the barriers to this happening has been a government policy determined to separate out the natural values from the productive values and place them under Crown ownership. It has been an unfortunate policy because it emphasised to farmers that the conservation of these values was not their responsibility. That is a dreadful message to people who should be encouraged indeed, expected to regard themselves as the guardians of the land for the future. The recent shift in approach by Government in relation to the High Country of the South Island is a welcome breath of fresh air. This might appear to be irrelevant to my topic but I am firmly of the view that the recognition and embracing of these values within our hill country enterprises will be an increasing expectation of our customers. And that will affect our balance sheets.

\section{Summary}

- Climate change, water availability for agriculture, and population growth are inevitable components of a global future.

- Global food supplies are going to tighten. Sheep meat is going to be a real beneficiary. Food prices are going to rise.

- NZ hill country farming systems have some huge competitive advantages, particularly around knowledge and know how.

- But markets, currency and climate are going to continue to be volatile.

- The successful enterprises out into the future will be conservative in their land use strategies and will have sophisticated risk management strategies.

- A continuing focus on an efficient grass-based system is imperative. The natural environment within which we farm is to be treasured both for its spiritual value and its monetary value.

- The ETS is a reality, we will be participants and must start looking at how to adjust to it.

If I were 20 years old again you wouldn't stop me wading in! 
